\title{
CT evaluation of vulnerable plaque: noninvasive fortune-telling?
}

\author{
Maksymilian P. Opolski • Cezary Kepka • \\ Adam Witkowski
}

Received: 29 March 2011/Accepted: 7 April 2011

(C) The Author(s) 2011. This article is published with open access at Springerlink.com

\begin{abstract}
Recently, cardiac CTA has been proposed as a promising noninvasive tool for identification of rupture-prone plaques prior to a subsequent coronary event. This task is particularly challenging but the reward is high: identification of high-risk lesions could preclude plaque thrombosis and possibly prevent acute coronary syndromes. We present a case of a borderline mixed plaque with positive remodeling in the proximal left anterior descending artery (LAD). After 6 months and despite aggressive medical therapy, the patient developed acute STelevation myocardial infarction caused by a thrombotic lesion in the proximal LAD. We review the literature on CT characteristics of vulnerable plaque and discuss the possible preventive interventions.
\end{abstract}

Keywords Computed tomography angiography . Vulnerable plaque $\cdot$ Plaque rupture $\cdot$ Acute coronary syndrome

M. P. Opolski ( $\square)$ · A. Witkowski

Department of Interventional Cardiology and Angiology, Institute of Cardiology, ul. Alpejska 42,

04-628 Warsaw, Poland

e-mail: maxopol@gmail.com

C. Kepka

Department of Coronary and Structural Heart Diseases, Institute of Cardiology, Warsaw, Poland

\section{Case in point}

A 59-year-old male with atypical chest pain and intermediate pretest probability underwent dualsource computed tomography angiography (CTA). CTA was performed with $80 \mathrm{ml}$ contrast agent at $6.0 \mathrm{ml} / \mathrm{s}, 100 \mathrm{kV}$ tube voltage and retrospective ECGgated protocol (slice thickness, $0.6 \mathrm{~mm}$; overlap, $0.4 \mathrm{~mm}$ ) with radiation exposure of $12.1 \mathrm{mSv}$. Multiplanar reconstructions demonstrated a borderline (60\% luminal stenosis) mixed plaque in the proximal segment of left anterior descending artery (LAD) and mild atherosclerotic lesions in the left circumflex and right coronary artery with total calcium Agatston score of 678 (Fig. 1a). Cross-sectional images of LAD demonstrated a mixed plaque with low attenuation area proximal to calcium spots and positive remodeling (Fig. 1b-f). Based on patient's preferences, aggressive medical therapy with a high-dose statin, aspirin and antihypertensive agents was initiated. After 6 months the patient presented with acute anterior ST-elevation myocardial infarction caused by thrombotic lesion in the proximal LAD (Fig. 1g, h). Although he underwent primary percutaneous coronary intervention of the culprit LAD, NYHA class II heart failure symptoms developed.

Plaque rupture and thrombus formation play key roles in the onset of acute coronary syndrome. Based on previous autopsy studies the majority of culprit lesions are typically nonstenotic, contain a large necrotic core with a thin overlying fibrous cap, and 


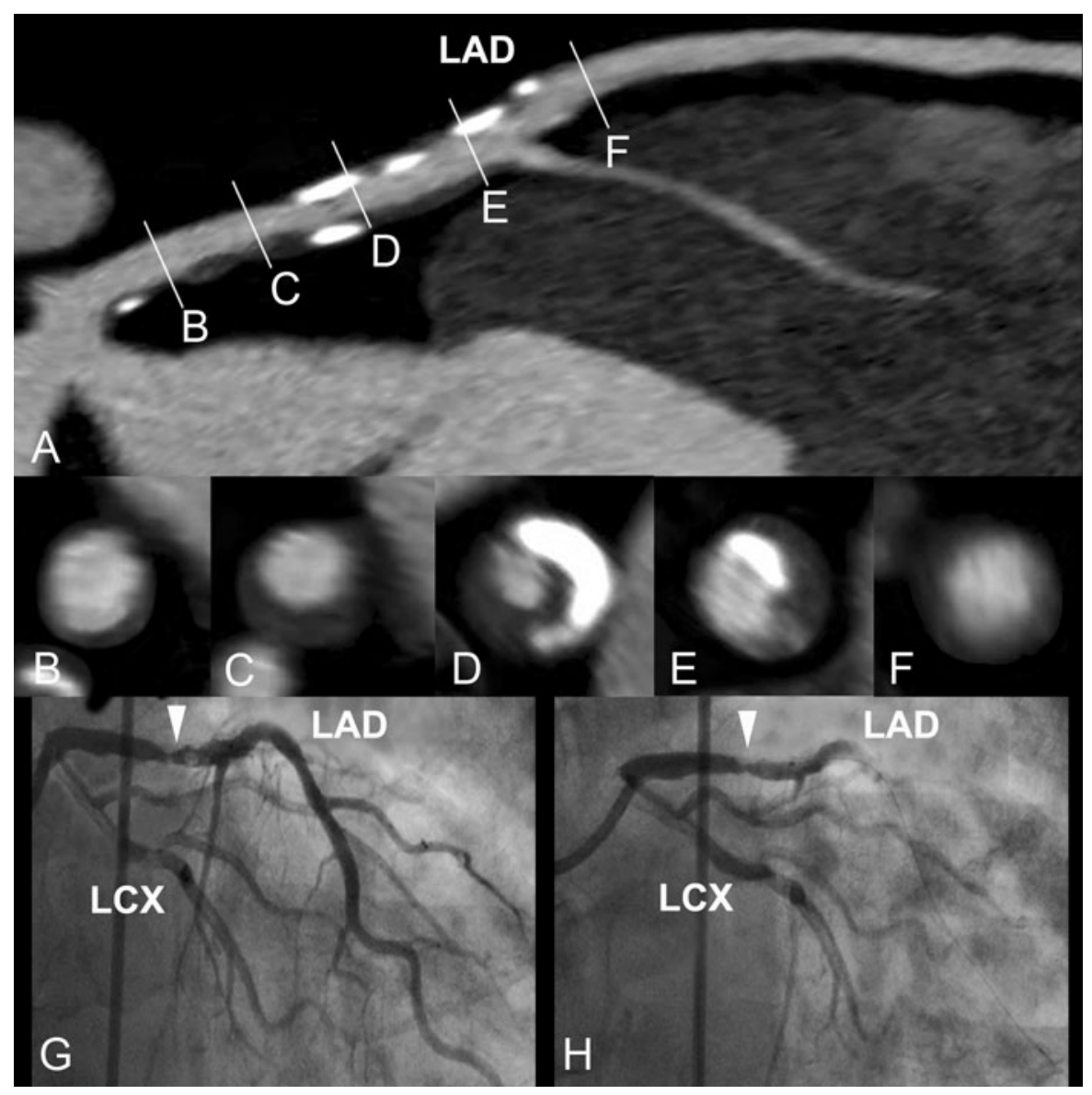

Fig. 1 a Curved multiplanar reconstruction of a high-risk lesion in the proximal left anterior descending artery (LAD) causing future ischemic event. b-f Serial cross sections demonstrating mixed plaque with low attenuation area

induce expansive remodeling of the vascular segment [1]. Recently, Stone et al. reported the results of a prospective study assessing the relationship between lesion characteristics and new cardiovascular events among previously stented subjects. In conclusion, although frequently angiographically mild most lesions causing future ischemic events were characterized by a large plaque burden $(\geq 70 \%)$ and/or small luminal area $\left(\leq 4.0 \mathrm{~mm}^{2}\right)$ as determined by intravascular ultrasonography [2].

Recently, cardiac CTA has been proposed as a promising noninvasive tool for identification of rupture-prone plaques prior to a subsequent coronary event. Pundziute et al. demonstrated that an increase in coronary segments with detectable non-obstructive plaques was associated with increased mortality. Furthermore, not only total plaque burden but also proximal to calcium spots and positive remodeling. $\mathbf{g}$, h Left coronary angiography showing high-grade thrombotic lesion (arrowheads) in the proximal LAD. $L A D$ left anterior descending artery, $L C X$ left circumflex

proximal plaque location was related to future ischemic events [3]. In the only CT study assessing plaque characteristics prior to major cardiovascular events, Motoyama et al. showed that plaques with low CT attenuation and positive remodeling are at particularly high-risk for rupture [4]. Indeed, in our case, the presence of mixed plaque with positive remodeling in the proximal segment of LAD was associated with development of subsequent acute coronary syndrome. Interestingly, we identify a specific type of vulnerable plaque distribution characterized by low attenuation area proximal to multiple calcium spots.

Certainly, with the widespread application of CTA and the advent of new low radiation CT scanners, noninvasive identification of rupture-prone plaques becomes technically feasible. However, the inclusion of "noninvasive fortune-telling" in future CTA 
Appropriateness Criteria would require conducting clinical trials focused on the development of tailored medical interventions for the prevention of plaque rupture. Currently, preventive or therapeutic management may include minimizing risk factors using life style changes, systemic drug therapy, or mechanical plaque sealing by coronary stenting. In our case, aggressive medical therapy did not prove beneficial in preventing future ischemic event, suggesting that conservative management is not always the right choice.

\section{Conflict of interest None.}

Open Access This article is distributed under the terms of the Creative Commons Attribution Noncommercial License which permits any noncommercial use, distribution, and reproduction in any medium, provided the original author(s) and source are credited.

\section{References}

1. Stary HC, Chandler AB, Dinsmore RE, Fuster V, Glagov S, Insull W Jr, Rosenfeld ME, Schwartz CJ, Wagner WD,
Wissler RW (1995) A definition of advanced types of atherosclerotic lesions and a histological classification of atherosclerosis: a report from the Committee on Vascular Lesions of the Council on Arteriosclerosis, American Heart Association. Circulation 92:1355-1374

2. Stone GW, Maehara A, Lansky AJ, de Bruyne B, Cristea E, Mintz GS, Mehran R, McPherson J, Farhat N, Marso SP, Parise H, Templin B, White R, Zhang Z, Serruys PW, PROSPECT Investigators (2011) A prospective naturalhistory study of coronary atherosclerosis. N Engl J Med 364:226-235

3. Pundziute G, Schuijf JD, Jukema JW, Boersma E, de Roos A, van der Wall EE, Bax JJ (2007) Prognostic value of multislice computed tomography coronary angiography in patients with known or suspected coronary artery disease. J Am Coll Cardiol 49:62-70

4. Motoyama S, Sarai M, Harigaya H, Anno H, Inoue K, Hara T, Naruse H, Ishii J, Hishida H, Wong ND, Virmani R, Kondo T, Ozaki Y, Narula J (2009) Computed tomographic angiography characteristics of atherosclerotic plaques subsequently resulting in acute coronary syndrome. J Am Coll Cardiol 54:49-57 